\title{
The Impact of Blockchain Technology on Food Waste Management in the Hospitality Industry
}

\author{
Asterios Stroumpoulis \\ University of Piraeus, Greece, Greece \\ Evangelia Kopanaki \\ University of Piraeus, Greece, Greece \\ Maria Oikonomou \\ University of Piraeus, Greece, Greece
}

\begin{abstract}
This paper examines blockchain technology and food waste management in the hospitality industry. Food waste prevention is an important issue for hotels, as food consumption is difficult to estimate, often leading to huge amounts of waste. Food waste occurs at each stage of the food supply chain and represents a big percentage of hospitality waste. Although many studies examine the difficulties of food waste management, only a limited number of studies examine the stages of food waste inside food supply chains. The coordination of food supply chains can be supported by blockchain technology, which can break the supply chain into smaller parts and help managers to better mitigate food control. To address these issues, this paper conducts an extensive literature review, firstly to clarify the concept of food waste management in the hospitality industry and secondly to examine the benefits of the use of blockchain technology in food supply chains. Combining the obtained knowledge, this study aims to analyze the relationship between blockchain and food waste management practices. It also aims to examine how this combination boosts hotels to increase their performance and gain customers' loyalty. Therefore, this paper analyses food waste management in the hospitality industry makes propositions on how blockchain technology could support food waste management in the food supply chain and forms the base for future research.
\end{abstract}

Keywords: blockchain technology, sustainable development, food supply chain, food waste management, hospitality industry

JEL classification: Z32

Acknowledgments: This work has been partly supported by the University of Piraeus Research Center.

Paper type: Research article

Received: Mar 13, 2021

Accepted: Jun 24, 2021

DOI: $10.54820 / C Q R J 6465$ 


\section{Introduction}

Food waste management has become an important field of academic research (Papargyropoulou et al., 2016). Food waste occurs through the whole food chain, from agricultural production to final consumption (Xue et al., 2017). It is a global phenomenon that can hinder or restrain sustainability, due to its undesirable impact on the environmental, social, and economic aspects of sustainability. This is the reason why United Nations have included food waste reduction in the Sustainable Development Goals (SDGs).

Food waste management is also of growing importance for the hospitality industry, as its operations produce large amounts of waste (Ball et al., 2011) creating a combination of ecological, economic, and social issues (Martin-Rios et al., 2018). Food waste is an essential part of hospitality waste with financial implications and environmental consequences (Williams et al., 2011). With the continuing growth of the industry, the production of food waste has increased dramatically (Massow et al., 2015). This is an important issue for hospitality companies, which strive to find ways to control it and reduce it, to decrease the negative socio-economic and environmental impact (Pirani et al., 2016), and to achieve sustainability goals.

As mentioned before, food waste occurs at every stage of the food supply chain. Partners within the food supply chain need to monitor and control food sharing as there is significant evidence that large quantities of food are wasted during the preparation and consumption stages (Betz et al., 2015). Information technology could support this process and enable the efficient collaboration of partners, within the food chain. Blockchain technology could also provide beneficial results. It could support every stage of the food supply chain and enable hospitality companies to increase their performance (Kucukusta, 2017). It could also enable them to implement strategies according to the three pillars of sustainable development (Saberi et al, 2019).

Although there is a significant amount of research examining food waste management (Siorak et al., 2015) in the hospitality industry, there is only a limited number of studies analyzing the role of new technologies and strategies in this context. Even more limited is the number of studies discussing the potential impact of blockchain technology on the collaboration of food supply chain partners and the handling of food waste.

Therefore, this paper aims to conduct a literature review to clarify the above concepts and to analyze the relationship between blockchain technology and food waste management in the hospitality industry. The paper discusses the potential impact of blockchain technology and suggests that hospitality companies and food supply chains could use it to increase their business performance and improve their environmental impact.

\section{Methodology}

The paper analyses the problem of food waste in the hospitality industry and examines the relationship between blockchain technology and food waste management. It also examines how this combination could enable hotel companies to gain operational efficiency, environmental consciousness, and customer loyalty.

To better understand, clarify and analyze the concepts addressed in this paper, it was necessary to conduct an extensive literature review. A literature review gives information about the papers published, and the theories developed in the subject under examination. A literature review is very useful, as it provides researchers with a summary of studies conducted in a specific scientific field (Hallinger, 2013). It also helps researchers to support their argument, while providing an original contribution 
(Pozzebon et al., 2011). Furthermore, it enables them to synthesize the scientific evidence transparently and identify research gaps, as a base for future research (Principato et al., 2021).

The steps, that were followed, include: searching for articles by keywords, narrowing the article selection by reading the abstracts, categorizing the articles, clarifying the meanings and the relationship among them, conclude and identifying the gaps in the literature for future research. The steps followed are presented in Figure 1.

The keywords used in the search are blockchain technology, food waste management, food supply chain, hospitality industry. The search was conducted mostly in google scholar, Scopus, and Researchgate databases. The total number of papers originally retrieved was 53. After reading their abstracts and skimming throw the papers, 42 of them were selected as being more relevant to this research. These papers were further categorized based on their content. More specifically, 17 papers examine blockchain technology, 14 analyze food supply chains and sustainable supply chain management, and 17 address the problem of food waste management. It should be noted that some papers examine a combination of these research areas.

Figure 1

Steps of Methodology

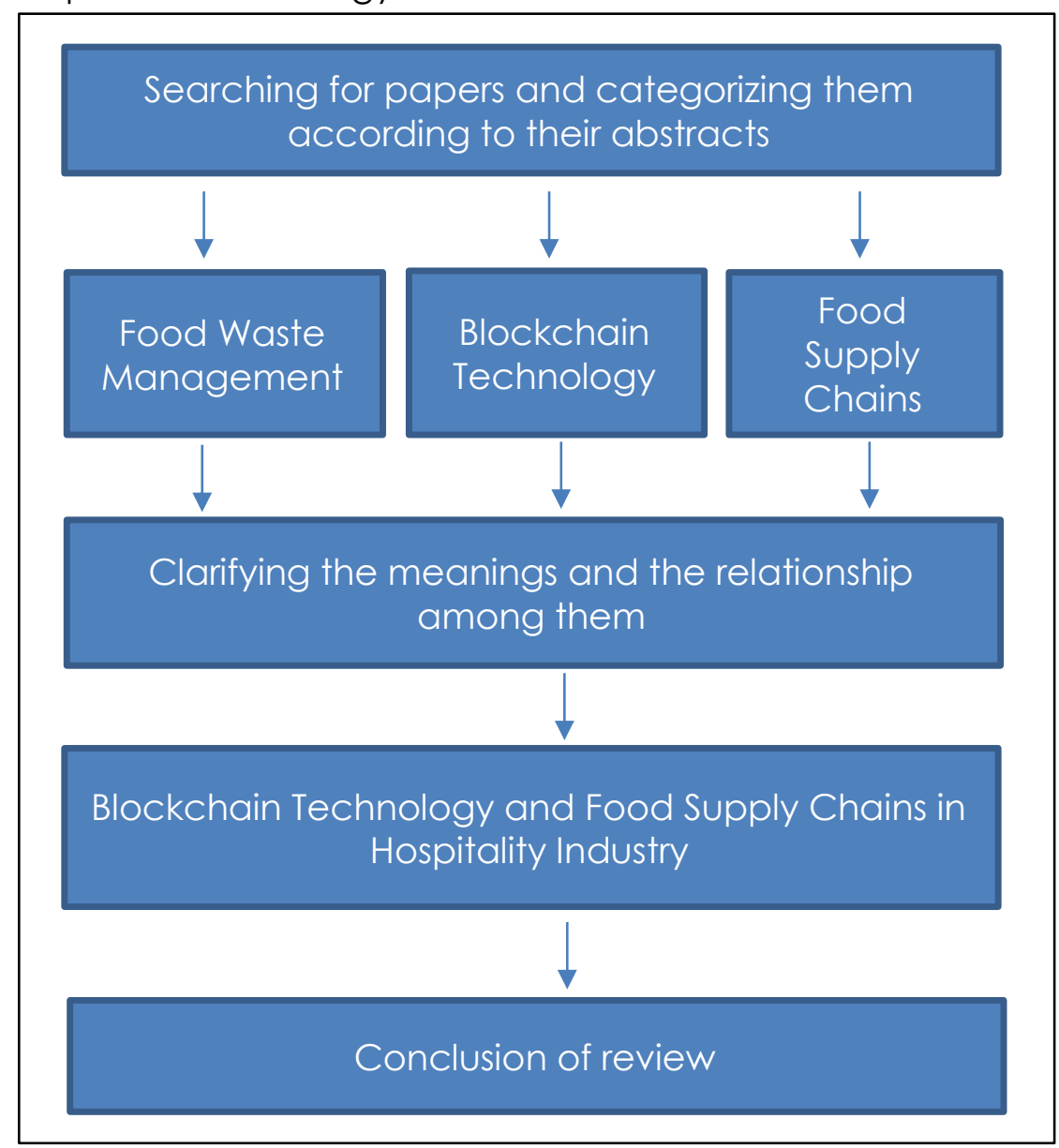

Source: Author's illustration

The extensive literature review enabled us to explain the main concepts and theories related to the subject of study. It also allowed us and develop a conceptual 
framework that presents the main factors enabling a hospitality company to increase its performance.

\section{Literature Review}

\section{Food Waste Management in the Hospitality Industry}

Food waste concerns a system of food production and consumption which is unsustainable. In the literature, there is not a general and wide acceptable definition of food waste, even though it concerns a major global problem (Martin-Rios et al., 2018). The definition adopted and used in this study was developed by the Food and Agriculture Organization (FAO) of the United Nations (FAO, 2014). According to FAO, food waste is defined as the amount of food unconsumed and thrown away in food-service chains (Gustavsson et al., 2011). During the different stages of food chains, such as storage, preparation, consumption, and serving, food can be wasted or lost (Betz et al., 2015).

During the post-harvest stages and the processing stages, including transport, storage, processing, and distribution, further food waste can occur (Martin-Rios et al., 2018). Retail also creates a significant amount of waste in the food supply chain (Aiello et al., 2014). Finally, consumption, which is the final stage of a food supply chain, is responsible for as much as $40 \%$ of total food losses (Beretta et al., 2013). Recent studies show that in developed countries, a large percentage of food waste occurs in the final stage of the food supply chain.

Land, water, effort, and energy that have been used during the stages of production and distribution of goods are also wasted when food is not consumed and thrown away (Thyberg et al., 2016). This creates additional implications related both to the environment and the economic pillar of sustainable development.

As mentioned above, food waste can be created during all stages of the food supply chain. Because actions of food waste reduction in one stage may create problems (Engström et al., 2004), stakeholders of all stages must collaborate to find a solution in that case (Halloran et al., 2014). The relationships deriving from the collaboration among the different stages of the food supply chain may lead to common strategies for sustainable development (Sonnino et al., 2011) and to innovative practices to improve food waste management (Derqui et al., 2016).

A possible solution to this problem could be the use of information technology and in particular the use of blockchain technology.

\section{Blockchain Technology}

Blockchain technology was used for the first time in the Bitcoin cryptocurrency (Ahram et al., 2017). Apart from cryptocurrency, blockchain is a new technology that started to have implications in supply chain management (Tian, 2016). According to Crosby et al. (2016), blockchain technology is "a distributed database of records or public ledger of all transactions or digital events that are executed and shared among participating parties". The key characteristics of blockchain technology are non-localization (decentralization), security, auditability, and smart execution (Saberi et al., 2019).

During the last years, blockchain technology is becoming more and more important and useful in many industries (such as the financial and the manufacturing sectors) and has been characterized as a game-changer (Yadav et al., 2020). Privacy, security, smart contracts (Christidis et al., 2016), and traceability, which are the main characteristics of this technology, can make supply chains more efficient. Therefore, the transactions among the involved partners of a chain can be improved by the implementation of BT (Kosba et al., 2016). 
Partners do not always develop collaborations with the best conditions. There are trust issues, due to inefficient transactions and fraud, which call for better information sharing. So, the solution to this problem will be the development of supply chain transparency, security, durability, and process integrity, through the use of blockchain technology within the supply chain (Saberi et al., 2019). Similar benefits could be obtained in the agriculture industry, which is still not so digitized (XU et al., 2019). For example, through the AgriDigital platform (first launched in Australia) trust between farmers and other members of the agricultural supply chains was increased by using this technology (Xu et al., 2019).

The potential use and impact of blockchain technology on supply chain management have been examined since the early stages of its appearance (Tribis et al., 2018). According to Xu et al. (2019) supply chains are characterized as a natural market for blockchains. The rate of growth of BT in supply chains is $87 \%$ annually and there will be an increase from $\$ 45$ million in 2018 to $\$ 3314.6$ million in 2023 (Chang et al., 2019).

\section{Blockchain Technology in Food Supply Chain of Hospitality Industry} Due to the globalization of food supply chains, there is a significant increase in product, food, and information sharing among countries (Behnke et al., 2020). Therefore, members of food supply chains aim to increase the transparency of their supply chains and improve the capability of tracing the products from farms to the final consumers (Kumar et al., 2020). Consequently, traceability and transparency of food supply chains have become critical to overcoming multiple problems occurring in global food supply chains (Rejeb et al., 2020). Traceability practices and systems, aiming to improve the operations of food supply chains, are widely used in the food industry (Casino et al., 2019). According to Dasaklis et al. (2019) traceability is regarded as a strategic tool, which can improve food safety, and lead to the creation of competitive advantage.

Blockchain could contribute to the food supply chains in the hospitality industry, by bringing results at all three pillars of sustainable development.

- As far as the social pillar is concerned, blockchain can ensure information integrity, which means that information cannot be modified at any stage, without the approval of the authorized partners (Saberi et al., 2019). Thanks to the transparency and traceability that blockchain provides, hospitality companies could monitor the status of food products at all stages of the supply chain. Therefore, food fraud could be prevented and food safety ensured.

- As far as the environmental pillar is concerned, blockchain enables detailed monitoring of transactions and tracking of products, reducing rework and recall (Saberi et al, 2019), and consequently leading to a reduction of energy consumption and environmental pollution.

- Finally, blockchain technology could contribute to the economic pillar of each partner, by dividing food supply chains into smaller chains with reduced transaction costs, fewer delays, and better control. It could also contribute to increased security of transactions (XU et al., 2019) preventing further expenses. Furthermore, providing all the necessary information could enable hospitality companies to choose more suitable and reliable partners (Mathew, 2018). Partners, in food supply chains, will be able to maintain transaction records to control and increase the integrity of all transactions between suppliers, retailers, customers, and other stakeholders (Shih et al., 2019). 
The impact of blockchain technology on the sustainability of supply chains and specifically of food supply chains are presented in Table 1.

Table 1

Blockchain Technology impact on sustainable Supply Chain Management

\begin{tabular}{ll}
\hline Blockchain Technology improvements in Food Supply Chains \\
\hline Society & - Transparency \\
& - Traceability \\
Environment & - Revention of fraud/food safety \\
& - Recrease of food waste \\
Economy & - Reduced transaction costs, \\
& - Fewer delays \\
& - Transaction security \\
\hline
\end{tabular}

Source: Author's illustration

\section{Discussion}

According to the literature review, presented in the previous chapter, blockchain technology is a new technology, which could bring added value to a company. It could provide a secure environment, supporting information sharing and informing all trading partners at any time and at any stage of the supply chain about potential changes or problems, which may require an immediate response or solution. Therefore, it could be considered as a strategic resource, which is not easily adopted and imitated, creating sustainable value for companies (Wernerfelt, 1984). It could also affect all three pillars of Sustainability, bringing benefits to a social, environmental, and economic level.

Thus, food supply chains could adopt blockchain technology to support sustainability practices. Besides the benefits identified in the literature, the use of blockchain could enable stakeholders to exchange information regarding all stages of food production or consumption, quickly identify changes and take actions to adjust supply with demand. It could also enable information sharing with food banks to facilitate the distribution of unconsumed food and reduce food waste.

Therefore, as demonstrated in Figure 2, blockchain technology could help the hospitality industry to better coordinate food supply chains, improve food waste management, and control food waste. Thus, hospitality companies could develop strategies to reach sustainable goals. This would help them to increase their customers' loyalty, as customers are more willing to buy and use products, that are greener than others, and from companies, which respect the environment and society (Bhattacharya et al., 2004). Moreover, using blockchain technology, companies could improve their environmental performance, by decreasing the environmental impact at each stage of food supply chains. Finally, they could increase their business performance, through reduced transaction costs, improved selection of partners, easier detection of fraud, and decreased frequency of recall of unsafe products. 
Figure 2

Blockchain Technology impact on companies

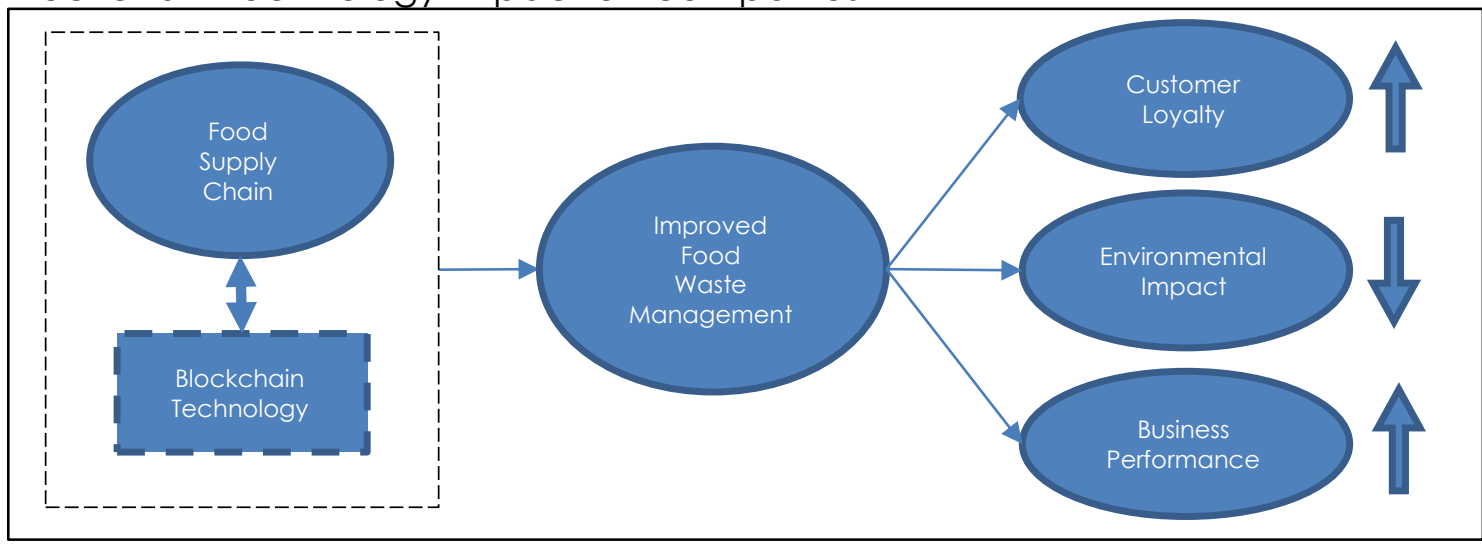

Source: Author's illustration

\section{Conclusion and limitations}

As it appears from the above analysis of the literature, blockchain technology could have a positive impact on food waste management in the hospitality industry. It can be used to track food problems from the first stages of their production to the final stage (that of consumption) and prevent food waste, fraud, and any other unethical practice or action, by making food supply chains more transparent. It can also provide customers and consumers with better information about the way food is developed and delivered, enabling them to make more environmentally friendly choices.

Due to the expected advantages, blockchain technology will possibly become an integral part of food supply chains, shortly. However, there is the main problem deriving from the requirement of a high degree of computerization, which prevents some partners from participating in blockchain-based solutions (Kshetri, 2018). Without their participation, it is difficult to realize the full potential of blockchain in food supply chains.

\section{References}

1. Ahram, T., Sargolzaei, A., Sargolzaei, S., Daniels, J., Amaba, B. (2017), Blockchain technology innovations. in 2017 IEEE technology \& engineering management conference (TEMSCON), Santa Clara IEEE, pp. 137-141.

2. Aiello, G., Mario, E., Muriana, C. (2014), "Economic benefits from food recovery at the retail stage: an application to Italian food chains", Waste Manage, Vol. 34 No. 7, pp. 1306-1316.

3. Ball, S., Taleb, A. M. (2011), "Benchmarking waste disposal in the Egyptian hotel industry", Tourism and Hospitality Research, Vol. 11 No. 1, pp. 1-18.

4. Behnke, K., Janssen, M. F. W. H. A. (2020), "Boundary conditions for traceability in food supply chains using blockchain technology", International Journal of Information Management, Vol. 52, pp. 1-10.

5. Beretta, C., Stoessel, F., Baier, U., Hellweg, S. (2013), "Quantifying food losses and the potential for reduction in Switzerland", Waste Manage, Vol. 33 No. 3, pp. 764-773.

6. Betz, A., Buchli, J., Göbel, C., Müller, C. (2015), "Food waste in the Swiss food service industry-magnitude and potential for reduction", Waste Manage, Vol. 35, pp. 218-226.

7. Bhattacharya, C. B., Sen, S. (2004)," Doing better at doing good: When, why, and how consumers respond to corporate social initiatives", California management review, Vol. 47 No. 1, pp. 9-24. 
8. Casino, F., Kanakaris, V., Dasaklis, T. K., Moschuris, S., Rachaniotis, N. P. (2019), "Modeling food supply chain traceability based on blockchain technology", Ifac-Papersonline, Vol. 52 No. 13, pp. 2728-2733.

9. Chang, Y., lakovou, E., Shi, W. (2019), "Blockchain in global supply chains and cross border trade: A critical synthesis of the state-of-the-art, challenges and opportunities", International Journal of Production Research, Vol. 58 No. 7, pp. 2082-2099.

10. Christidis, K., Devetsikiotis, M. (2016), "Blockchains and smart contracts for the internet of things", IEEE Access, Vol. 4, pp. 2292-2303.

11. Crosby, M., Pattanayak, P., Verma, S., Kalyanaraman, V. (2016), "Blockchain Technology: Beyond Bitcoin", Applied Innovation, No. 2, pp. 6-9.

12. Dasaklis, T. K., Casino, F. (2019), "Improving Vendor managed Inventory Strategy Based on Internet of Things (IOT) Applications and Blockchain Technology", in 1st IEEE International Conference on Blockchain and Cryptocurrency.

13. Derqui, B., Fayos, T., Fernandez, V. (2016), "Towards a more sustainable food supply chain: opening up invisible waste in food service", Sustainability, Vol. 8 No. 7, pp. 1-20.

14. Engström, R., Carlsson-Kanyama, A. (2004), "Food losses in food service institutions Examples from Sweden", Food policy, Vol. 29 No. 3, pp. 203-213.

15. FAO (2014), Global Initiative on Food losses and Waste Reduction, FAO, Rome.

16. Gustavsson, J., Cederberg, C., Sonesson, U., Van Otterdijk, R., Meybeck, A. (2011), Global Food Losses and Food Waste, FAO, Rome, Italy.

17. Hallinger, P. (2013), "A conceptual framework for systematic reviews of research in educational leadership and management", Journal of Educational Administration, Vol. 51 No. 2, pp. 126-149.

18. Halloran, A., Clement, J., Kornum, N., Bucatariu, C., Magid, J. (2014), "Addressing food waste reduction in Denmark", Food Policy, Vol. 49, pp. 294-301.

19. Kosba, A., Miller, A., Shi, E., Wen, Z., Papamanthou, C. (2016), "Hawk: the blockchain model of cryptography and privacy-preserving smart contracts", in 2016 IEEE Symposium on Security and Privacy (SP), San Jose, pp. 839-858.

20. Kshetri, N. (2018). "I Blockchain's roles in meeting key supply chain management objectives", International Journal of Information Management, Vol. 39, pp. 80-89.

21. Kucukusta, D. (2017), "Chinese travelers' preferences for hotel amenities", International Journal of Contemporary Hospitality Management, Vol. 29 No. 7, pp. 1956-1976.

22. Kumar, A., Liu, R., Shan, Z. (2020), "Is blockchain a silver bullet for supply chain management? Technical challenges and research opportunities", Decision Sciences, Vol. 51 No. 1, pp. 8-37.

23. Martin-Rios, C., Demen-Meier, C., Gössling, S., Cornuz, C. (2018), "Food waste management innovations in the foodservice industry", Waste management, Vol. 79, pp. 196-206.

24. Massow, M. V., McAdams, B. (2015), "Table scraps: An evaluation of plate waste in restaurants", Journal of Foodservice Business Research, Vol. 18, pp. 437-453.

25. Mathew, S. (2018), "Blockchain is a game changer in supply chain", available at: https://supplychaingamechanger.com/blockchain-in-the-supply-chain-is-a-gamechanger/ (21 May 2021)

26. Papargyropoulou, E., Wright, N., Lozano, R., Steinberger, J., Padfield, R., Ujang, Z. (2016), "Conceptual framework for the study of food waste generation and prevention in the hospitality sector", Waste management, Vol. 49, pp. 326-336.

27. Pirani, S. I., Arafat, H. A. (2016), "Reduction of food waste generation in the hospitality industry", Journal of Cleaner Production, Vol. 132, pp. 129-145.

28. Pozzebon, M., Petrini, M., de Mello, R. B., Garreau, L. (2011), "Unpacking researchers' creativity and imagination in grounded theorizing: An exemplar from IS research", Information and Organization, Vol. 21 No. 4, pp. 177-193.

29. Principato, L., Mattia, G., Di Leo, A., Pratesi, C. A. (2021), "The household wasteful behaviour framework: A systematic review of consumer food waste", Industrial Marketing Management, Vol. 93, pp. 641-649.

30. Rejeb, A., Keogh, J. G., Zailani, S., Treiblmaier, H., Rejeb, K. (2020), "Blockchain Technology in the Food Industry: A Review of Potentials, Challenges and Future Research Directions", Logistics, Vol. 4 No. 4, pp. 1-26. 
31. Saberi, S., Kouhizadeh, M., Sarkis, J., Shen, L. (2019), "Blockchain technology and its relationships to sustainable supply chain management", International Journal of Production Research, Vo. 57 No. 7, pp. 2117-2135.

32. Shih, D. H., LU, K. C., Shih, Y. T., Shih, P. Y. (2019), "A simulated organic vegetable production and marketing environment by using Ethereum", Electronics, Vol. 8 No. 11, pp. 1-18.

33. Siorak, N., Demen Meier, C., Buri, S., Cornuz, C. (2015), "International and national regulations in favour of sustainable operations in food service", in Sloan, P., Legrand, W. (Eds.), The Routledge Handbook of Sustainable Food, Beverage and Gastronomy. Routlegde, Abingdon, pp. 379-390.

34. Sonnino, R., McWilliam, S. (2011), "Food waste, catering practices and public procurement: A case study of hospital food systems in Wales", Food Policy, Vol. 36 No. 6 , pp. 823-829.

35. Thyberg, K. L., Tonjes, D. J. (2016), "Drivers of food waste and their implications for sustainable policy development", Resources, Conservation and Recycling, Vol. 106, pp. 110-123.

36. Tian, F. (2016), "An Agri-food Supply Chain Traceability System for China Based on RFID \& Blockchain Technology", in 13th International Conference on Service Systems and Service Management, ICSSSM, Kunming, pp. 1-6.

37. Tribis, Y., El Bouchti, A., Bouayad, H. (2018), "Supply chain management based on blockchain: A systematic mapping study", in MATEC web of conferences (EDP sciences) 200.

38. Wernerfelt, B. (1984), "A resource-based view of the firm", Strategic management journal, Vo. 5 No. 2, pp.171-180.

39. Williams, P., Leach, B., Christensen, K., Armstron, G. D., Hawkins, R. P., Lane, A. J. G., Scholes, P. (2011), "The Composition of Waste Disposed of by the UK Hospitality Industry", Report RES093-001, Waste and Resources Action Programme, London.

40. Xu, X., Weber, I., Staples, M. (2019), Architecture for blockchain applications, Springer, Cham.

41. Xue, L., Liu, G., Parfitt, J., Liu, X., Van Herpen, E., Stenmarck, Å., Cheng, S. (2017), "Missing food, missing data? A critical review of global food losses and food waste data", Environmental science \& technology, Vol. 51 No. 12, pp. 6618-6633.

42. Yadav, S., Singh, S. P. (2020), "Blockchain critical success factors for sustainable supply chain", Resources, Conservation and Recycling, Vol. 152, 104505. 


\section{About the authors}

Asterios Stroumpoulis is a Survey Engineer. He holds a BSC in Survey Engineering and an MSc. in Transport Systems from the Faculty of Engineering of Aristotle University of Thessaloniki in Greece. Moreover, he holds an M.B.A. degree, and he is a Ph.D. Candidate at the Department of Business Administration of the University of Piraeus. His research interests include various areas such as Information Systems, Sustainable Development, Competitive Advantage, Business Performance, Business Operations, Logistics, Supply Chain Management. He participated in the following project, "Development and management of a destination management system (DMS) at Regional level of the Peloponnese". The author can be contacted at stergiostrou@unipi.gr

Dr. Evangelia Kopanaki is an Assistant Professor at the University of Piraeus. She holds a BSC. in Mathematics and an MSC. in Computer Science from the National and Kapodistrian University of Athens. She also holds a Ph.D. in Information Systems from the London School of Economics and Political Science, Department of Management, Information Systems and Innovation Group. Her research interests lie in the areas of e-business, supply chain management, and web information systems. She has published various research papers and books on e-business and web technologies. She participated in various research projects related to the development and use of ICTs in various industries. The author can be contacted at evik@unipi.gr

Maria Oikonomou studied Economics, and she is an MBA graduate of the University of Piraeus. Today, she is a Ph.D. candidate at the Department of Business Administration of the University of Piraeus. Her Ph.D. research topic is "The support of business activities by Mobile Business to create and maintain a competitive advantage. She has participated in international conferences on Entrepreneurship and Management and also in Business Projects by European Union. She gives seminars in Entrepreneurship, Innovation, and Mobile Business. She participated in the project "Development and management of a destination management system (DMS) at Regional level of the Peloponnese". Her contact email address is: moikonomou@unipi.gr 